\title{
O DEBATE SOBRE IDEOLOGIA E PRODUÇÃO DE CONSENSOS NA ORDEM BURGUESA EM MÉSZÁROS
}

Gláucia Lelis Alves ${ }^{1}$

\begin{abstract}
Resumo: este artigo tem por objetivo refletir acerca da ideologia dominante e sua funcionalidade à reprodução da ordem burguesa, mediada pelo papel do Estado de produzir consensos falseados em torno da necessidade da conciliação como escamoteamento da luta de classes. A análise aqui apresentada resgata as categorias Estado e ideologia à luz do pensador húngaro marxista István Mészáros. O sistema do capital assume uma função totalizadora no controle das instituições e de todas as esferas da vida social. Nesse sentido, a apologia apregoada pelo sistema é a de que ele comporta estratégias altamente democráticas, tanto do ponto de vista econômico, quanto político. Nesse processo, o Estado constitui-se como esfera de comando e dominação, daí a necessidade de desvelar suas contradições e as estratégias ideo-políticas de sua legitimação.
\end{abstract}

Palavras-Chave: Estado - Ideologia - Consensos - Alienação

\section{THE MÉSZÁROS' DEBATE ON IDEOLOGY AND PRODUCTION OF CONSENSUS IN THE BURGUES ORDER}

\begin{abstract}
: this article aims to reflect on the dominant ideology and its functionality to the reproduction of the bourgeois order, mediated by the role of the State to produce distorted consensus around the need for conciliation as a concealing of the class struggle. The analysis here presented rescues the categories of State and ideology in the thought of the Hungarian Marxist thinker István Mészáros. The capital system assumes a totalizing function in the control of institutions and of all spheres of social life. In this sense, the apology proclaimed by the system is that it involves highly democratic strategies, both economically and politically. In this process, State is constituted as a sphere of command and domination, hence the need to unveil its contradictions and the political-ideological strategies of legitimation.
\end{abstract}

Keywords: State - Ideology - Consensus - Alienation

\footnotetext{
1 Doutora em Serviço Social pela Pontifícia Universidade Católica de São Paulo (PUC-SP). Atua como Professora Adjunta da Escola de Serviço Social da Universidade Federal do Rio de Janeiro (UFRRJ). E-mail: glaucialelisalves@gmail.com
} 


\title{
EL DEBATE SOBRE IDEOLOGÍA Y PRODUCCIÓN DE CONSENSOS EN LA ORDEN BURGUESA EN MÉSZÁROS
}

\begin{abstract}
Resumen: el presente artículo tiene por objetivo reflexionar acerca de la ideología dominante y su funcionalidad con la reproducción del orden burgués, mediado por el papel del Estado al producir consensos falseados en torno a la necesidad de conciliación como ocultamiento de la lucha de clases. El análisis aquí presentado rescata las categorías de Estado e ideología a la luz del pensamiento del húngaro István Mészáros. El sistema de capital asume una función totalizadora en el control de las instituciones y de todas las esferas de la vida social. En ese sentido, la apología pregonada por el sistema señala que él mismo funciona mediante estrategias altamente democráticas, tanto desde el punto de vista económico, como político. En este proceso el Estado se constituye como esfera de comando y dominación, de ahí la necesidad de revelar sus contradicción y las estrategias ideo-políticas de su legitimación.
\end{abstract}

Palabras Clave: Estado - Ideologías - Consensos - Alienación

\section{Introdução}

Na monumental obra de István Mészáros, um dos mais importantes pensadores marxistas dos séculos XX-XXI, podem ser destacadas diferenciadas dimensões indispensáveis ao entendimento do contexto contemporâneo de desenvolvimento do capitalismo. Dentre elas a discussão acerca da incontrolabilidade do sistema sociometabólico capitalista, que se orienta pela expansão e se estrutura pela acumulação; o Estado como estrutura totalizadora de comando político do capital e os mecanismos de controle social; a atualidade e a necessidade de fortalecimento do projeto socialista como único caminho a ser trilhado ao rompimento dessa ordem societária, no sentido de vislumbrar um modo diferente de intercâmbio social em uma perspectiva histórica e totalizante.

Uma de suas maiores contribuições, no entanto, refere-se ao debate - tão propício e elucidativo do processo de decadência político-ideológica em curso na quadra histórica que se desenrola a partir do século XXI - acerca do estratégico deslocamento político-ideológico do conflito de classes para a conciliação operado pelo Estado burguês e sua função de corrigir os limites relativos e absolutos produzidos pelo capital, tais corretivos de pouco efeito, situam-se no campo do reformismo e da força repressiva estatal. Tais elementos serão discutidos no texto que se apresenta, com o objetivo de evidenciar a questão do Estado e da ideologia como estratégias para pensar as relações sociais em tempos de extrema decadência ideológica operada pelo projeto conservador. 


\section{A questão do Estado e a estratégia corretiva aos defeitos estruturais do sistema sociometabólico do capital}

O processo de reprodução sociometabólica do capital assume uma dimensão totalizadora na vida social que se complexifica, cada vez mais, por meio do movimento do capital e de seu caráter destrutivo. 0 capital revela-se não só como entidade material, mas como forma incontrolável do controle sociometabólico.

Segundo Mészáros (2002),

a razão principal por que este sistema forçosamente escapa a um significativo grau de controle humano é precisamente o fato de ter, ele próprio, surgido no curso da história como uma poderosa - na verdade, até o presente, de longe a mais poderosa - estrutura 'totalizadora' de controle à qual tudo o mais, inclusive seres humanos, deve se ajustar, e assim provar sua 'viabilidade produtiva', ou perecer caso não consiga se adaptar (MÉSZÁROS, 2002, p. 96).

Nesse sentido, a apologia apregoada pelo sistema é a de que ele comporta estratégias altamente democráticas tanto do ponto de vista econômico, quanto político. Paradoxalmente, as estratégias de tomada de decisão e o controle da vida social perdem-se, em razão da capacidade de complexificação do sistema do capital. Outro ponto relevante para o fortalecimento das estratégias de controle e consolidação do projeto totalizador do sistema do capital é o próprio Estado como esfera de comando e dominação. 0 Estado complementa o potencial totalizador do capital, e ambos são componentes do controle sociometabólico do capital. Uma das estratégias para consolidar esse controle, considerando a dualidade entre divisão da sociedade em classes e controle político, ocorreu por meio da divisão social hierárquica do trabalho, e separação das funções de produção e de controle do processo de trabalho.

Por outro lado, para além dessa estratégia, fez-se necessário o controle ideológico para a manutenção do poder, como por exemplo, para justificar a desigualdade socialmente criada pelo sistema, considerada como algo natural. Esse processo, em virtude da determinação do sistema do capital, que deve se orientar para a expansão e se mover pela acumulação, gerou outro, que é permeado pela incontrolabilidade dessa mesma expansão. De acordo com Mészáros (2002, p. 101), "graças a sua incontrolabilidade, o capital conseguiu superar todas as desvantagens que se opuseram a ele [...] elevando seu modo de controle metabólico ao poder de dominância absoluta como sistema global plenamente estendido". Alteraram-se assim, as formas de controle sociometabólico que, nas sociedades antigas e medievais, se moviam pela autossuficiência no relacionamento entre produção 
material e seu controle, para consolidar a difusão universal da alienação e da reificação.

Na sociedade burguesa, o trabalhador não é entendido como homem em seu tempo livre de trabalho, ele somente se constitui como homem, como trabalhador proletário, em seu tempo de trabalho. 0 trabalhador, nesse contexto, é reduzido às suas estritas necessidades corporais, o que representa uma concepção restrita da condição do humano. Concepção que se constrói e se legitima em decorrência da lógica burguesa que permeia as relações sociais, a produção e reprodução social pela dinâmica perversa estabelecida entre mercado, mercadoria, lei da oferta e da procura e livre concorrência, que perpassam a relação entre trabalhadores e a própria concepção de trabalho da sociedade burguesa.

Na análise da mercadoria e do papel central que exerce no sistema do capital, articulam-se alienação, fetichismo e reificação, pois a mercadoria constitui elemento fundamental da estrutura do capitalismo moderno, em todas as suas manifestações vitais. Nesse sentido, efetiva-se uma objetividade fantasmagórica em que as relações entre pessoas tomam o caráter da relação entre coisas, ocultando a essência fundamental da sociabilidade humana, ou seja, a própria relação que se estabelece entre os homens.

Para que a forma mercantil seja exercida no interior da estrutura social, é preciso, além de torná-la forma constitutiva dessa sociedade, "penetrar [...] no conjunto das manifestações vitais da sociedade e remodelar tais manifestações à sua própria imagem" (LUKÁCS, 2003, p. 196), ir além das relações entre valor de uso e valor de troca. Com o capitalismo moderno, instituiu-se a mercantil como forma de dominação efetiva, pela reificação, que então surge, no que se refere à submissão da consciência do homem à mistificação produzida no conjunto das relações mercantis. Para Lukács (2003, p. 199), “o homem é confrontado com sua própria atividade, com seu próprio trabalho como algo objetivo, independente dele e que o domina por leis próprias, que lhes são estranhas. E isso ocorre tanto sob o aspecto objetivo, quanto sob o subjetivo".

Nessa equação, a força de trabalho assume também a forma de mercadoria, objetivada nessa dinâmica. Essa forma reificada, extrema, constitui-se no fetichismo da mercadoria, no contexto próprio do capitalismo. Como assinala o autor,

é como categoria universal de todo ser social que a mercadoria pode ser compreendida em sua essência autêntica. Apenas nesse contexto a reificação surgida da relação mercantil adquire uma importância decisiva, tanto para o 
desenvolvimento objetivo da sociedade quanto para a atitude dos homens a seu respeito, para a submissão de sua consciência às formas nas quais essa reificação se exprime. (LUKÁCS, 2003, p. 198)

As formas de reificação e a objetivação fantasmagórica da mercadoria expressamse na fragmentação do processo de trabalho, pela redução do trabalho a funções mecânicas, repetitivas, reiterativas, em operações parciais, bem como, pelo processo de racionalização do tempo de trabalho necessário, quebrando a unidade do produto como valor de uso. A outra dimensão desse processo refere-se ao sujeito, ou seja, o homem passa a constituir-se como parte mecanizada, e o processo de trabalho aparece, de forma mistificadora, apartado do ser social. Nessa dimensão, efetiva-se efetiva sua fragmentação. A redução do espaço e tempo a um mesmo denominador em virtude da racionalização e mecanização do processo de trabalho, em que o tempo é tudo quanto possa ser mensurado, calculado, pela especialização das funções e, ao mesmo tempo em que se fragmenta o objeto e os sujeitos do trabalho.

Somente no âmbito do capitalismo, constitui-se o processo de racionalização e mercantilização do trabalho, e essa característica distingue-o das outras formas de sociabilidade, pela universalização da esfera mercantil. Na universalidade das relações mercantis, a satisfação das necessidades humanas torna-se circunscrita à troca de mercadorias, separando o produtor dos seus meios de produção, substituindo as relações humanas por relações reificadas, e a base da reificação é o caráter desumanizado e desumanizante da relação mercantil. Como um processo que se institui pela capitalização radical de toda a sociedade, pela extração da maisvalia, pelo capital financeiro, mercantil, o capital constituiu-se como formas autênticas representantes da vida social dos homens, pela sua consciência reificada.

Nessa dimensão, situa-se a lógica fetichizadora do capital, que se complementa como relação social entre coisas, e o exemplo claro dessa dinâmica expressa-se na relação dinheiro-lucro-juro. Meszáros (2002, p. 102) analisa que "o capital como produtor potencial de valor historicamente específico só pode ser consumado e 'realizado' [...] se penetrar no domínio da circulação", redefinindo a relação entre produção e consumo. Essa dinâmica de liberação da autossuficiência na relação produção-consumo modificada pela circulação no sistema do capital potencializa-se com a mistificação produzida com base no trabalho livre contratual.

Essa mistificação refere-se à relação entre alienação e fetichismo intensificada no sistema do capital. 0 problema do fetichismo - expressão mais complexa dos processos de alienação - apresenta-se se na confluência entre trabalho e valor, o que redunda na materialização da mercadoria, ou seja, na contradição própria do sistema 
capitalista contemporâneo, e, ao mesmo tempo em que se explicita o caráter social do trabalho, ele é escamoteado por um caráter associal. Trata-se a fantasmagoria consolidada pela equação entre relações sociais no processo de produção-relações entre coisas, apreendida na sua factualidade/naturalização.

O fetichismo é parte constitutiva da função totalizadora do capital, pois ele se afirma e se desenvolve cristalizando-se em coisas, escamoteando as relações sociais com base em coisas, mercadorias, no contexto próprio de consolidação extrema do capitalismo, potencializando-se na financeirização do capital, sua dimensão atual. Na análise de Mészáros (2002), o fetichismo manifesta-se porque o próprio sistema do capital é um sistema de controle "sem sujeito", em decorrência dos processos reificantes que se instauram nos processos de trabalho, na conversão da satisfação das necessidades humanas, por meio de mercadorias e do fetiche que exerce. Nesse sentido, imperam as determinações e os imperativos objetivos do capital em detrimento das necessidades humanas. Os representantes desse sistema não são mais do que personificações do capital. Além disso, a base da alienação permeia o controle dos produtores, e

o sistema do capital se baseia na alienação do controle dos produtores. Neste processo de alienação, o capital degrada o trabalho, sujeito real da reprodução social, à condição de objetividade reificada - mero "fator material de produção" - e com isso derruba, não somente na teoria, mas na prática social palpável, o verdadeiro relacionamento entre sujeito e objeto (MÉSZÁROS, 2002, p. 127)

Assim, a dimensão totalizadora do capital que vem se plasmando historicamente, em suas condições de reprodução, revela que os processos alienantes expressos na reificação e no fetichismo penetram na totalidade das relações de produção social e nas relações que viabilizam a sua reprodução. Universaliza-se a factualidade resultante da mistificação realizada pela mercadoria nas relações sociais. Em nome da função totalizadora, constitui-se o Estado moderno, complementando o que Mészáros (2002) chama de metabolismo socioeconômico do capital. Há que se destacar a incontrolabilidade desse processo global de expansão, pois, nele, o capital constrói formas variadas de controle no campo da produção, da ideologia, da cultura, da educação, e assim por diante.

Os processos alienantes também passam por uma expansão mundial, pois é preciso assegurar a manutenção desse sistema, função exercida também pelo Estado capitalista que, para Mészáros (2002), constitui-se na estrutura totalizadora do comando político do capital. Indaga-se então nessa análise se mesmo diante das contradições e da incontrolabilidade do capital (seu caráter destrutivo), como o 
sistema do capital reconstrói suas bases de sustentação, ou seja, quais as estratégias atuais para sua reprodução ideológica, econômica e social. Há que se considerar que o sistema ainda não esgotou sua capacidade de exploração e, consequentemente, de manipulação construída pelos processos alienantes. Evidencia-se ainda que já se alcança um processo de maximização da produção e ampliação do trabalho morto. Esse processo gera também consequências em termos econômicos e políticoideológicos, pois há exploração do trabalhador de forma ampliada tanto na esfera da produção, como na esfera do consumo.

Dentre os problemas gerados pela incontrolabilidade do sistema do capital, ressaltam-se questões no campo da separação e antagonismo entre produção e controle, ruptura entre produção e consumo e a ausência de unidade entre produção e circulação, e, para dar "certa" unidade, é fundamental o poder exercido pelo Estado moderno. De acordo com Mészáros (2002 p. 107), “o Estado moderno constitui a única estrutura corretiva compatível com os parâmetros estruturais do capital como modo de controle sociometabólico. Sua função é retificar". No processo de expansão global do capital, da sua capacidade de dominação, e instaura-se o papel do Estado.

Ao mesmo tempo em que o sistema do capital se expande em todos os níveis, tanto no que se refere às estratégias de extração do trabalho vivo quanto ao controle ideopolítico das relações sociais, seu processo de expansão produz uma perda de controle no que se refere à reprodução social, em virtude da incontrolabilidade dessa expansão. 0 sistema por si só constitui-se em uma forma incontrolável de controle sociometabólico.

Mészáros (2002) define controle sociometabólico como defeitos estruturais de controle do capital. Para o autor, o defeito estrutural do controle profundamente enraizado está localizado na ausência de unidade. Essa ausência assume a forma de antagonismos sociais expressos com maior ou menor intensidade, em razão das circunstâncias históricas em que foram produzidas.

Esses defeitos manifestam-se com base em elementos tais como: a) necessidade de estruturação da sociedade com base em antagonismos, considerando a separação entre produção e controle do processo de trabalho; b) característica da incontrolabilidade inerente ao sistema, o que faz prever o potencial de sua autodestruição; c) extrema separação entre produção e consumo, produzindo desumanização exacerbada; d) ampliação da necessidade de controle - nos planos locais, regionais e nacionais - para a sujeição da força de trabalho total da humanidade aos imperativos alienantes do sistema do capital global. 
Consolida-se uma estrutura corretiva para tais defeitos estruturais. Esta estrutura refere-se ao Estado moderno, como já dito anteriormente, instância que, de certa forma, complementa a estrutura totalizadora do capital. Dessa forma,

no que se refere à possibilidade de administrar a separação e o antagonismo estruturais de produção e controle, a estrutura legal do Estado moderno é uma exigência absoluta para o exercício da tirania nos locais de trabalho. Isso se deve à capacidade do Estado de sancionar e proteger o material alienado e os meios de produção [...] e suas personificações, os controladores individuais [...] do processo de reprodução econômica (MÉSZÁROS, 2002, p. 107).

Para garantir o processo de mudanças foram introduzidas estratégias no controle da burguesia sobre as crises cíclicas do capitalismo, e a maioria delas assumiu um caráter reformista, a exemplo da implantação do keynesianismo (que tinha por objetivo conter as crises por meio de ações governamentais). Destaca-se a funcionalidade dessas mudanças por ocasião da alteração do padrão produtivo fordista-keynesiano para o toyotista, com o intuito de maximizar a exploração da força de trabalho, bem como flexibilizar o processo de acumulação.

Assim, todas as relações são permeadas pela determinação das condições de funcionamento do mercado capitalista, ou seja, há uma busca incessante pela produtividade em todos os campos, e, tendo em vista aperfeiçoar o gerenciamento das crises, o princípio da empregabilidade reproduz a desvalorização do direito ao trabalho, a lógica competitiva é revalorizada, e o ser social passa a ser visto como um indivíduo consumidor. Desse modo, há uma mercadorização dos direitos, com a estreita relação entre mercado e Estado:

o papel diversificado do mercado nas diferentes fases de desenvolvimento do sistema do capital, desde os intercâmbios limitados até o mercado mundial completamente realizado, é totalmente incompreensível sem relacioná-lo ao outro lado da mesma equação: a dinâmica igualmente variável do Estado como estrutura de comando político totalizadora (MÉSZÁROS, 2002, p. 120).

Da mesma forma, as inovações tecnológicas são consolidadas para servirem aos interesses do capital, como estratégia para a ampliação do Estado burguês (controle da informação) e sofisticação da política armamentista, bem como o estímulo à subordinação do homem em relação à máquina. Nessa perspectiva de análise, o Estado tem como papel primordial, em sua corporificação coesiva, garantir a expansão e a extração de trabalho excedente e, dessa forma, a extração da mais-valia. Ao efetivar esse papel, "reforça a dualidade entre produção e controle e também a divisão hierárquico/estrutural do trabalho de que ele próprio é uma clara manifestação". (MÉSZÁROS, 2002, p. 120). Há uma recusa em desvelar a 
realidade social, e regimes sociais transformam desemprego em lazer e produtividade em meios de fazer viver, sem revelar os perigos e responsabilidades das mudanças empreendidas pelo capital, nesse contexto, também não se evidencia o conflito.

No entanto, as estratégias de correção dos defeitos estruturais produzidos pelo sistema, sobretudo no que se refere às tendências de equalização do índice diferencial de exploração e do crescente autoritarismo nos Estados, antes liberais, e, consequentemente, pelo desencantamento geral com a política democrática, não dão conta de eliminar os antagonismos do capital social total. Qualquer forma de harmonização ou equilíbrio nos conflitos é temporária, e a concepção burguesa defende o equilíbrio de forças, considerando que esses antagonismos situam-se nas condições estruturais do próprio sistema. Há uma determinação recíproca entre as dimensões econômicas e políticas, escamoteada pelos processos alienantes em uma reciprocidade dialética. Mészáros (2002) esclarece:

O que está em questão aqui é o fato de que o capital é seu próprio sistema de comando, de que é parte integrante a dimensão política, ainda que de modo algum parte subordinada. [...] vemos aqui a manifestação prática de uma reciprocidade dialética. [...] 0 Estado [...] deve ser entendido como parte integrante da própria base material do capital. Ele contribui de modo significativo não apenas para a formação e a consolidação de todas as grandes estruturas reprodutivas da sociedade, mas também para seu funcionamento ininterrupto. [...] o Estado moderno em si é totalmente inconcebível sem o capital como função sociometabólica. (MÉSZÁROS, 2002, p. 124-125)

Ainda a respeito dessa reciprocidade, o autor destaca que há uma correspondência estreita entre, "[de] um lado, a base sociometabólica do sistema do capital e, [de] outro, o Estado moderno como estrutura totalizadora de comando político da ordem produtiva e reprodutiva estabelecida". (idem)

Nessa dinâmica, escamoteia-se ainda uma das principais contradições inerentes ao funcionamento do sistema do capital, ou seja, ele se constitui como um sistema de controle sem sujeito, como já dito anteriormente, e necessita ainda de exercer o domínio/controle dos produtores, reificando-os. Porém, como reduzir e anular o sujeito real da produção? 0 capital faz por meio de mediações, e, nesse campo efetiva-se o papel do Estado:

é ele quem oferece a garantia fundamental de que a recalcitrância e a rebeldia potenciais não escapem ao controle. Enquanto esta garantia for eficaz (parte na forma de meios políticos e legais de dissuasão e parte como paliativo para as piores conseqüências do mecanismo socioeconômico produtor de pobreza, por meio dos recursos do sistema de seguridade social), o Estado moderno e a ordem reprodutiva 
sociometabólica do capital são mutuamente correspondentes. (MÉSZÁROS, 2002, p. 127)

No bojo dessas contradições, situa-se a necessidade, cada vez maior, de controle do processo de produção, porque há uma tendência de crescimento da socialização da produção, que confere maior capacidade de controle aos produtores. É o que autor denomina dissonância estrutural entre o sistema e a formação do Estado. Outra contradição refere-se à capacidade totalizadora desse Estado que - com o intuito de garantir a irrestringibilidade global do capital - não consegue abranger a totalidade das unidades socioeconômicas reprodutivas existentes no capital ao considerar que há particularidades e especificidades no processo de formação dos estados nacionais e na interação entre eles. Dessa forma as contradições produzidas na base do sistema e os seus defeitos estruturais não serão superados unicamente por meio da intervenção política, nem tampouco pela economia de mercado sem que haja mudanças fundamentais na ordem sociometabólica das sociedades pósrevolucionárias (MÉSZÁROS, 2002).

No que se refere à configuração atual do processo de controle sociometabólico do capital, o sistema passa das pequenas unidades produtivas fragmentadas para gigantescas corporações transnacionais de sua plena articulação global, o que, de certa maneira, desafia a garantia de seu domínio ideo-político. Assiste-se a um processo de financeirização da economia, expressa pela consolidação, a partir da década de 1960, de um mercado mundial do dinheiro. Há uma mercadorização desenfreada das relações sociais. Em sua nova fase, esse processo tem como características principais a ampliação das funções financeiras das corporações, transnacionalização dos bancos e empresas, dentre outras. Essa expressão do capital financeiro efetiva-se com a fusão de grandes bancos e empresas industriais e comerciais, bem como com agentes governamentais.

Com base no modelo neoliberal, a reforma do Estado deve orientar-se para o mercado, abandonando instrumentos de controle político, restringindo a alocação dos recursos públicos, diminuindo as funções do Estado e fortalecendo as ações de natureza privada. 0 mercado passa a ser o espaço da garantia da eficiência e eficácia não obtidas no espaço público. Essa dinâmica envolve também a efetivação da política social que passa a se organizar pelos princípios da focalização (voltada para setores de extrema pobreza), pela descentralização (instituem-se formas de gestão locais) e pela privatização. E, ainda, sua efetivação é permeada pelo princípio da menor elegibilidade (ligado a mecanismos de seletividade) e pela incerteza do não direito. 
Dessa forma, é equivocado afirmar que o processo de mundialização suprime ou anula a importância do Estado como esfera reguladora das relações sociais; ao contrário, a função de comando político estatal intensifica-se, modificando-se para acompanhar a plasticidade da ordem do capital, estendendo seu poder às instituições financeiras. Essa dinâmica expressa uma contradição do sistema, pois o processo de financeirização do capital exige, cada vez mais, a intervenção estatal, com o objetivo de administrar as crises do sistema financeiro. Nessa mudança na direção do Estado, ampliam-se e intensificam-se também a transferência de riquezas e a precariedade do trabalho, agravam-se os processos de extração da mais-valia, da reificação, da flexibilização do trabalho, em decorrência da ampliação das dívidas públicas para conter as crises das empresas e finanças. Para resolver essa equação, são absolutamente funcionais os mecanismos ideológicos.

\title{
Processos alienantes e produção de consensos na racionalidade burguesa
}

\begin{abstract}
em nossas sociedades tudo está "impregnado de ideologia", quer a percebamos, quer não. [...] em nossa cultura liberal-conservadora o sistema ideológico socialmente estabelecido e dominante funciona de modo a apresentar - ou desvirtuar - suas próprias regras de seletividade, preconceito, discriminação e até distorção sistemática como "normalidade", "objetividade" e "imparcialidade científica". (MÉSZÁROS, 2004, p. 57)
\end{abstract}

$\mathrm{Na}$ histórica estratégia ideo-política de escamoteamento da luta de classes, evidencia-se a produção e a legitimação de um discurso de naturalização da desigualdade social, bem como a tese do fim dos antagonismos entre capital e trabalho, em que o trabalhador passa a ter o controle do processo de trabalho. 0 escamoteamento referido diz respeito à banalização do humano pelo predomínio do capital fetiche, expressa na subversão do humano e no desenvolvimento de uma barbárie social.

Mészáros (2004) define esse processo como camuflagem ideológica enganadora, em que o Estado incontestavelmente se constitui como força inexorável por meio da conformidade política e ideológica, disseminando, estrategicamente, como ideologia única, a perpetuação do capital. A questão de impor uma uniformidade ideológica para esse fim estende-se também à democracia e à liberdade ocidentais.

Esse processo compõe a programática da ideologia dominante para afirmar-se em todos os níveis, porque esta tem o controle das instituições políticas e culturais da sociedade. Uma das estratégias é a negação da luta/conflito de classes, a busca da 
reconciliação, e um exemplo dela é a afirmação de que os problemas de necessidade econômica são técnicos, e sua solução depende da gerência de especialistas capacitados para tal. É importante não ignorar o poder da ideologia para a (re)produção do sistema. Desse modo, não se deve conceber a ideologia como superstição, como mito, mas como consciência social materialmente ancorada e sustentada. No bojo dos processos ideológicos, de construção da consciência social, do processo de tomada de consciência dos conflitos sociais é que são definidos e problematizados os interesses sociais, os projetos societários. Segundo Mészáros (2004, p. 65),

os interesses sociais que se desenvolvem ao longo da história e se entrelaçam conflituosamente manifestam-se, no plano da consciência social, na grande diversidade de discursos ideológicos relativamente autônomos [...] que exercem forte influência sobre os processos materiais mais tangíveis do metabolismo social.

A construção e a predominância de um discurso ideológico em relação ao outro dependem da sua capacidade de difusão e de legitimação totalizadora, sobretudo no espaço em que se instaura o conflito, o âmbito da própria estrutura social. 0 conflito explicitado refere-se ao potencial de controle regulador das práticas produtivas e distributivas da sociedade e a pretensa solução do conflito refere-se ao potencial de controle na disputa entre forças antagônicas.

No conjunto das práticas sociais, na equação entre os processos de luta e as formas ideológicas orientadas para a prática, provavelmente, encontram-se as bases para a solução ou não dos conflitos. Assim, "o que determina a natureza da ideologia, acima de tudo, é o imperativo de se tornar praticamente consciente do conflito social fundamental [...] com o propósito de resolvê-lo pela luta" (MÉSZÁROS, 2004, p. 65). Com base nessa análise, apreende-se que os discursos ideológicos não constituem meras abstrações, não são tipos ideais, mas manifestam-se, materializam-se nas práticas sociais, na mobilização e nas ações dos sujeitos coletivos. Há, portanto, a necessidade de identificá-los, no bojo da luta de classes, nos projetos societários em disputa.

Para Mészáros (2004, p.65), "trata-se de compreender como as características estruturais fundamentais de uma ordem social se afirmam na escala pertinente e circunscrevem os modos alternativos de conceituação de todos os problemas práticos mais importantes".

Além disso, devem-se identificar, no campo das determinações estruturais, os instrumentos de controle social e como são apropriados pelos sujeitos sociais rivais, 
na equação entre crítica/negação e/ou afirmação/sustentação, conforme os interesses que as forças sociais em disputa sustentam. As ideologias são construídas e determinadas historicamente, dependendo de dois elementos fundamentais. Um refere-se ao caráter antagônico das estruturas sociais que demarcam as construções ideológicas, ou seja, a consciência social prática das sociedades de classes é ideológica; o outro, corresponde so modo como, historicamente, são consolidadas as práticas produtivas e distributivas da sociedade que produzem a necessidade de imposição ou não de determinadas relações socioeconômicas e político-culturais.

Uma época histórica determina os limites do questionamento acerca da continuidade ou não de determinadas relações socioeconômicas e político-culturais. Nesse aspecto, situam-se o desafio ideológico e o próprio exercício do controle social. Assim, as concepções ideológicas são compatíveis com as épocas históricas às quais pertencem, com a consciência social da prática das sociedades de classe e com o tipo de conhecimento com o qual se vinculam.

Mészáros (2004) destaca nesse processo três posições ideológicas: a)a forma de organização societal vigente como horizonte absoluto da própria vida social; b) a forma da sociedade de classes como anacrônica, revelando ser irracional, análise de Rousseau; c) a posição ideológica que questiona a viabilidade da sociedade de classes propondo a sua superação, logo a superação desses antagonismos.

Nesse sentido, a conformação dos processos ideológicos é permeada pelos limites impostos pela perspectiva de classe, o que é inevitável. E ainda cabe um esclarecimento: do ponto de vista da práxis, deve-se intentar a superação das estratégias de uniformização e a negação do conflito social, disseminadas pela ideologia dominante. Para consolidar as bases da terceira concepção, é preciso repensar a prática social, por meio da articulação da consciência social como uma ideologia coerente e vigorosa.

Essa concepção de construção ideológica está presente no texto de Marx e Engels, A ideologia alemã. Segundo Konder (1981, p. 66-67), nessa obra, Marx e Engels destacam que o indivíduo não pode ser concebido fora do quadro da vida social, e o processo do conhecimento só pode ser devidamente entendido [...] quando relacionado com esta contínua intervenção ativa dos homens no mundo. Não é verdade que exista de um lado o mundo e de outro a consciência [...]. A tarefa de interpretar o mundo faz parte da tarefa maior de modificá-lo. 
Marx e Engels, conforme Konder (1981), situam nesse texto uma ciência histórico-materialista em oposição à filosofia, uma perspectiva mais ampla e amadurecida em relação aos Manuscritos econômico-filosóficos. Essa concepção é mediada pela noção da práxis, - expressão do ser humano humanizado e sua capacidade transformadora - que se realiza pelo trabalho, pela ação produtora.

Na exposição da Ideologia Alemã, os outros constroem uma crítica aos jovens hegelianos, com o intuito de questionar o papel da filosofia e da economia política no que se refere à ordem burguesa. A construção teórica explícita é que há vinculação entre os pressupostos reais e as próprias condições materiais de vida dadas pela realidade produzidas pela ação dos indivíduos, ou seja, não se trata de abstrações nem de dogmas. Na análise de Raniére (2000, p. 156), A Ideologia alemã preconiza como condição ontológica a necessidade de compreensão e acompanhamento do desenvolvimento histórico concreto, desde o momento em que se articula o material, o concreto e o intelectual, tendo em vista produzir as bases para o devir humano. Nesse sentido, há uma exposição analítica da composição das estruturas sociais, em uma tentativa de extrair o significado teórico da dialética, o que justifica o combate com os filósofos hegelianos de esquerda e a ruptura com a leitura hegeliana da realidade, bem como uma continuidade à teoria da alienação, em outra perspectiva.

Marx e Engels (2007) expõem seu método de investigação, ao estabelecerem a unidade entre matéria e pensamento, bem como suas contradições. Nas palavras dos autores,

totalmente ao contrário da filosofia alemã que desce do céu à terra, aqui se eleva da
terra ao céu; quer dizer, não se parte daquilo que os homens dizem, imaginam ou
representam, tampouco dos homens pensados para, a partir daí, chegar aos homens
de carne e osso; parte-se dos homens realmente ativos e, a partir de seu processo de
vida real, expõe-se também o desenvolvimento dos reflexos ideológicos e dos ecos
desse processo de vida. [...] os homens, ao desenvolverem sua produção e seu
intercambio materiais, transformam também, com esta sua realidade, seu pensar e
os produtos do seu pensar. Não é a consciência que determina a vida, mas a vida que
determina a consciência (MARX; ENGELS, 2007, p. 94).

Por outro lado, os autores explicitam seu conteúdo ontológico no processo de leitura histórica do complexo societário, ao mesmo tempo em que se opõem ao idealismo, com uma concepção coerente e vigorosa de perspectiva ideológica. Com base na crítica ao idealismo e na ruptura com o materialismo antropológico de Feuerbach, Marx e Engels (2007) constituem as bases do materialismo históricodialético, bem como elementos importantes ao desvelamento da perspectiva totalizadora do capital e as condições necessárias ao seu enfrentamento pela dimensão da emancipação humana. 
Dessa forma, retomam a questão fundamental no que se refere ao processo de consolidação das diferentes concepções ideológicas e a predominância de uma ou outra na sociedade de classes e as bases para a superação de seus antagonismos. Mészáros (2004, p.68) reafirma o principal dilema que atravessa, historicamente, essa necessidade. Para o autor "a questão prática [...] permanece a mesma, ou seja, 'resolver pela luta' o conflito fundamental relativo ao direito estrutural de controlar o metabolismo social como um todo".

Na contramão dessa perspectiva, evidencia-se que a ideologia dominante vem consolidando uma tendência à atenuação anistórica do conflito, sobretudo no que se refere à questão da modernidade e ao uso problemático do termo moderno, desprezando a dimensão sócio-histórica. Como exemplo, Mészáros (2004) destaca que Hegel, paradoxalmente, explicitou bem essa perspectiva ao preservar, pela exaltação idealista da atualidade racional do existente - a ordem capitalista moderna -, pela eternização ideológica dessa ordem e pregando a permanência atemporal de uma entidade a serviço da atenuação dos conflitos - o Estado alemão moderno.

Outro exemplo refere-se à influência metodológica e ideológica da teoria weberiana, que se fortaleceu após a Segunda Guerra Mundial, com base no princípio da racionalidade. Nessa dimensão de análise, a modernidade é definida em oposição à sociedade tradicional. A teoria weberiana estabelece, como princípio básico da oposição entre moderno e tradicional e de organização da sociedade pelo capital, a possibilidade do cálculo racional, anulando as ambiguidades e os antagonismos, incluindo o principal deles, a determinação estrutural da exploração de classe, com uma análise tipologicamente científica.

Para Mészáros (2004), o quadro conceitual típico-ideal definido por Weber apresenta-se falsamente como o paradigma da racionalidade. "Weber trata todos os sintomas de crise da ordem socioeconômica capitalista eternizada como meros 'desvios' em relação a sua racionalidade intrínseca como sistema total", diz o autor (p. 74).

O pensamento social construído por Max Weber foi profundamente difundido e, ao mesmo tempo, era funcional à legitimidade da estratégia ideológica do capitalismo na Segunda Guerra Mundial, constituindo-se como um dos principais representantes da democracia liberal, por causa de sua construção teórica sobre a racionalização, do cálculo e da eficiência burocrático-administrativa. Dessa forma, associaram-se eficazmente lucro e cálculo racional, bem como autonomização dos valores, ou seja, a sua definição destes dava-se divorciada dos grupos sociais e 
indivíduos. Sua funcionalidade vinculava-se ainda ao fortalecimento da luta aberta contra o socialismo de orientação marxista, com base no princípio da não superabilidade do capitalismo e do fracasso das experiências socialistas.

Para Mészáros (2004, p. 211),

Weber tornou-se o 'homem para todas as estações' do capitalismo do século XX porque traçou linhas de demarcação engenhosas, que se harmonizavam com as necessidades intelectuais da época, à medida que elas surgiam de acordo com as novas circunstâncias [...] [e] tentou alcançar isso com duas estratégias intelectuais complementares. A primeira consistia em uma extrema relativização dos valores [...] [e a segunda referia-se à articulação de] uma metodologia para opor radicalmente a constituição de 'visões de mundo' ao reino do conhecimento factual.

Segundo Mészáros (2004) alguns cruzamentos teóricos e adaptações foram estrategicamente articulados, para difundir uma visão de mundo referente à nova potência mundial, os Estados Unidos da América e propagar uma ordem social tranquila, dando fim à luta de classes. Alguns intelectuais assumiram esse papel, entre eles, Aron (conservadorismo liberal); Parsons; Merleau-Ponty. Para o autor (2004, p. 219), "havia uma base comum mais do que suficiente entre as novas necessidades ideológicas e a teoria weberiana original para tornar seu renascimento no pós-guerra viável e eficaz em sua orientação atlanticista específica". Esses cruzamentos, porém, não se deram de forma homogênea e devem ser resguardadas as diferenças de seus objetivos sociopolíticos.

Assim, o princípio dominante do capital no Estado ocidental moderno efetiva-se por um processo cultural de investimento no capital privado. Nessa perspectiva ideológica, de tipo weberiano, são desistoricizadas as contradições sócio-históricas e transformadas em características estruturais da relação entre modernidade e racionalização que, por sua vez, ocupa lugar central nessa análise.

E, ainda, com a perspectiva ideológica quase unilateral e reducionista da influência weberiana, que, pela equação irracionalidade-racionalidade, justifica os problemas e contradições da sociedade industrial moderna, renovadas pela Escola de Frankfurt, na leitura habermasiana e duramente criticada por Mészáros, no seguinte trecho:

a natureza da ordem socioeconômica do capital só é inteligível em termos globais, não se pode dar muito crédito à conceitualização do 'mundo capitalista avançado' a partir de uma perspectiva que ignora sistematicamente a esmagadora maioria da humanidade e opera com categorias que não dão atenção às suas condições de existência (MÉSZÁROS, 2004, p. 79) 
Outro aspecto relevante refere-se ao falseamento do consenso expresso, segundo o autor, na teoria da ação comunicativa de Habermas. Assim, difundem-se a possibilidade e a pretensa concretização de um diálogo espontâneo e não condicionado. Em outras palavras cria-se uma ilusão da possibilidade de um diálogo entre iguais, em uma mesma condição, o que na verdade escamoteia o jogo instituído nas relações de poder. Em vez do possível consenso há a imposição unilateral das relações de poder dominante "que assume muitas vezes a enganosamente nãoproblemática forma de um intercâmbio comunicativo 'produtor de concordância'" (MÉSZÁROS, 2004, p. 79). A dinâmica da capacidade de produção de concordâncias e consensos depende de como o sistema a incorpora ou lhe concede espaço e como essa concessão produz dividendos no processo produtivo.

Há que se considerar ainda a controvérsia entre modernidade e pósmodernidade, ou seja, desloca-se o debate para questões meramente metodológicas, anulando-se as questões sociais e políticas relativas ao processo organizativo da sociedade capitalista. Retoma-se a questão do consenso e de suas possibilidades de efetivação, desde o final da Segunda Grande Guerra. Tanto as chamadas teorias modernas quanto pós-modernas não foram capazes de indicar, segundo Mészáros (2004), forças possíveis de emancipação individual e social, por negarem a via da emancipação pelo caminho do trabalho, e, ainda, pelos problemas referentes à temporalidade histórica dos acontecimentos. Explicitam então tendências no campo das estratégias ídeo-políticas de dominação, fatores de manipulação institucionalizada, provocando reducionismos, tendo em vista a atenuação de conflitos.

Para garantir a atenuação dos conflitos mudam-se as estratégias, materializam-se uma multiplicidade e variedade de um novo discurso ideológico, do fim da ideologia, do fim da sociedade do trabalho, dentre outros. Mészáros (2004, p. 105) assinala:

Dessa maneira as ideologias adaptadas às novas circunstâncias podiam assumir uma postura levemente crítica com relação às manifestações superficiais do sistema em crise, sem sujeitar à crítica real os antagonismos internos fundamentalmente explosivos da ordem estabelecida.

A razão é que ainda escamoteia a relação dialética entre o complexo de produção das necessidades sociais e as manifestações cultural-ideológicas dele extraídas historicamente. Esse escamoteamento foi intensificado com a hegemonia norteamericana após 1945, e também com a perspectiva ideológica e cultural que reduz ainda mais o raio de atuação da teoria crítica. Esse processo expressa que as manifestações ideológicas, quase sempre, obedecem a interesses sociais 
dominantes, porque dominam espaços estratégicos de difusão de ideologias que restringem a leitura da realidade a uma perspectiva idealista que anula as implicações práticas dos conflitos sociais.

Também as demandas dos movimentos sociais mobilizam discursos ideológicos, ou seja,

o discurso ideológico orientado para si mesmo e predominantemente abstrato de um
período histórico específico [...] não aparece simplesmente da própria ideologia. Tem
sua origem nas contradições e crises historicamente específicas dos movimentos
sociais potencialmente emancipatórios e no relacionamento problemático entre
estes movimentos sociais e as ações cultural-ideológicas atuantes na sociedade
(MÉSZÁROS, 2004, p. 115).

Há, portanto, a necessidade de ampliar a perspectiva de análise, segundo a qual a ideologia resulta da consciência prática das sociedades, e somente na perspectiva prática e material é que se pode identificar a construção dos discursos ideológicos, sua legitimidade e suas crises. Historicamente, a questão do consenso vem permeando o processo de consolidação das relações de poder e se configurou como estratégia significativa no capitalismo monopolista, a partir do final da Segunda Grande Guerra. Nesse período, houve uma transição estratégica “da dividida arena socioeconômica das relações de classe [...] para a pseudoconcreticidade da esfera política em si" (MÉSZÁROS, 2004, p. 145) Essa dinâmica foi construída pela necessidade premente do Estado de administrar os conflitos e as "disfunções", e nesse espaço instituiu-se uma perspectiva conservadora de controle social

Nesse caso, o consenso constituído refere-se à legitimidade da utopia administrativa, da administração científica do Estado neocapitalistaintervencionista como a única alternativa, período denominado por Mészáros (2004) de consenso político posterior à guerra, pois era necessário instituir o capitalismo "organizado e livre de conflitos". Uma das estratégias consolidadas refere-se à difusão de um discurso do fim da ideologia, por associar as opiniões relacionadas às modificações socioeconômicas e políticas a manifestações ideológicas. Associada a essa outra, configurou-se a justificativa da necessidade de renovar a alienação como algo necessário e natural ao sistema, sendo o Estado o responsável pela função de controle das relações sociais.

Outras tendências foram demarcadas no processo de articulação das estratégias ideológicas e político-econômicas para a produção de consensos tendo por fundamento a base conceitual weberiana. Polêmicas e junções acerca da ideologia e das necessidades consensuais constituíram-se historicamente, com relação à prática 
política e intelectual, ao papel do Estado e ao processo organizativo da sociedade civil, bem como às estratégias ideológicas produzidas nesse campo de disputas.

Na contracorrente das ideologias dominantes da ordem social estabelecida, há ideologias críticas, produzidas por intelectuais que se situam no campo da contraconsciência, porém, estão em condições desiguais no processo de difusão de suas estratégias e discursos ideológicos, porque as ideologias dominantes detêm uma posição privilegiada, por terem o controle e o apoio das principais instituições econômicas, políticas e culturais do sistema. Essa desigualdade leva a desvantagens, pois faz com que a posição dos intelectuais, expressa nas suas construções teóricas e em sua praticabilidade, seja percebida como completamente negativa, com um ataque excessivo às instituições.

De acordo com Mészáros (2004, p. 234),

a negatividade de sua resposta [...] resulta de uma debilidade interna da posição crítica assumida. Primeiro, porque a dialética da negação e da afirmação é rompida em favor de uma negação unilateral que necessariamente permanece dependente do objeto negado para poder se definir. E, segundo, porque o desafio de articular de modo abrangente a teoria alternativa - tanto no plano da ação individual quanto no da ação coletiva juntamente com todos os complexos instrumentais e institucionais requeridos para sua implementação prática - não pode ser evitado.

Por outro lado, essa negatividade não depende somente de uma escolha teóricometodológica, ela está dada historicamente e só pode ser convertida em uma base de referência positiva a partir do momento em que indiquem, identifiquem e legitimem uma força hegemônica potencial. Dessa forma,

as ideologias críticas e as formas de 'contraconsciência' não podem deixar de ser parciais e unilateralmente negativas em sua autodefinição, a menos que possam oferecer uma alternativa hegemônica viável às práticas predominantes nessa formação estatal, em todos os planos da vida social. (MÉSZÁROS, 2004, p. 234))

Os apontamentos acima evidenciados demonstram, cada vez mais, a necessidade de retomar a questão da alienação e sua funcionalidade ao processo de expansão e reprodução do sistema do capital. Destaca-se que a sociabilidade burguesa produz estranhamento e alienação; nela se comprometem todas as possibilidades de construção de uma nova sociabilidade humana, em razão da alienação do trabalho, da dissociação entre trabalhador e os meios de produção, entre produção e consumo. Dessa forma, o trabalho e a vida tornam-se alienados, a sociedade burguesa, em vez de formar, deforma, desumaniza, por meio do trabalho alienado, descaracterizando o ser humano. 
Há que se construir uma organização societal para além do capital com base no processo mesmo de apreensão desse sistema por dentro dele, com suas contradições e limitações/fragilidades, de modo a desvendar os limites da ação política e o processo organizativo da classe trabalhadora. A perspectiva marxiana, com base na teoria social crítica, reafirma a tese de que é preciso superar a ordem societal burguesa, ainda com novas formas de consenso no campo das lutas sociais.

Na análise marxiana, a ação política é restrita e restritiva e não consegue abarcar todos os elementos essenciais para a construção da nova ordem societal, sobretudo quando permanece centrada somente na questão da esfera do poder em espaços societais delimitados, ou em momentos conjunturais específicos, e, assim, ocorrem a unilateralidade e os limites à legitimação de uma nova força hegemônica. Para a construção da nova ordem societal, é necessária uma revolução social e não apenas política.

A organização da ação política da classe trabalhadora mostra-se insuficiente para a construção da nova ordem societal, ou seja, nos processos revolucionários e nas tentativas de organizações já apontadas historicamente há uma cisão entre o político e o social. É preciso expandir a atuação do movimento socialista e da classe trabalhadora para além da dimensão parlamentar, que restringe seu campo de lutas à conquista do poder pelo Estado. Torna-se necessário instituir formas de resistência e rebeldia, formas de luta e enfrentamento em escala mundial. No rastro da tradição marxiana, Mészáros (2005, p. 60) aponta a necessidade de superação da sociedade do capital, e, para o autor, "é possível superar a alienação com uma reestruturação radical das nossas condições de existência há muito estabelecidas e, por conseguinte, de toda a nossa maneira de ser".

Em virtude do caráter incontrolável e destrutivo da expansão capitalista apontado, Mészáros (1995) destaca a atualidade da ofensiva socialista, ou seja, não é pela solução reformista e pela ampliação democrática mediante mecanismos de participação e controle social, nos moldes em que ela é implementada, que serão operadas mudanças significativas tanto na conformação de uma sociedade civil autônoma, com potencial crítico e argumentativo, como na conformação de um projeto emancipador de sociedade, em decorrência da crise estrutural vigente. No entanto, essa transição dependerá de ações dos homens, do processo organizativo da classe trabalhadora. Para Mészáros (2002), "a passagem do capitalismo para uma sociedade emancipada é caracterizada [...] como a passagem de uma forma de controle sociometabólico regida pelo capital à outra, controlada pelas necessidades humanas" (p. 792). Por isso, a revolução socialista não pode ser concebida como um 
ato singular, não importa quão seja radical na sua intenção. Ela deve ser descrita, como uma revolução social que se desdobra consistentemente autocrítica, isto é, como uma revolução permanente, capaz de prover e fazer o modo de controle autodeterminado da ordem socialista.

Faz-se necessário romper a atitude defensiva em que a classe trabalhadora se encontra, na perspectiva sindical e dos demais espaços de controle social operário; e, ainda, desenvolver a capacidade de autogestão da sociedade, com plena distribuição de poder, consolidando outro processo de democratização. 0 processo de formação da classe trabalhadora e dos demais segmentos sociais, nos moldes em que Mészáros (2002) caracteriza como a produção de uma contraconsciência, perpassa estratégias de rearticulação do projeto que apresenta como premissa uma sociedade sem classes, ou seja, aquela em que o sujeito deve eliminar-se como classe para realizar a nova ordem, isto é, deixar de ser classe e se constituir como livre produtor autônomo. E certamente nós não podemos nos dar ao luxo de vagar por outro século e meio no beco sem saída de tentar produzir mudanças estruturais no interior dos confins paralisantes do sistema do capital” (MÉZÁROS, 2002, p. 793).

\section{Referências}

ALVES, Gláucia Lelis. Controle social: expressão do reformismo conservador ou da luta pelo fortalecimento da democracia? São Paulo: 2010. Tese (Doutorado em Serviço Social) - Programa de Estudos Pós-graduados em Serviço Social, Pontificia Universidade Católica de São Paulo (PUC-SP).

KONDER, Leandro. Marx. Vida e obra. 4. ed. Rio de Janeiro: Paz e Terra, 1981.

LUKÁCS, György. História e consciência de classe. Estudos sobre a dialética marxista. Trad. Rodnei Nascimento. Rev. da trad. Karinna Jannini. São Paulo: Martins Fontes, 2003.

MARX, Karl; ENGELS, Friedrich. Ideologia Alemã. Critica da mais recente filosofia alemã em seus representantes Feuerbach, B. Bauer e Stirner, e do socialismo alemão em seus diferentes profetas. 1845-1846. Tradução de Rubens Enderle. São Paulo: Boitempo Editorial, 2007. 
MÉSZÁROS, István. Para além do capital. Trad. Paulo César Castanheira/Sérgio Lessa. São Paulo: Boitempo Editorial, 2002.

A teoria da alienação em Marx. Trad. Isa Tavares. São Paulo: Boitempo Editorial, 2006.

0 poder da ideologia. Trad. Paulo César Castanheira. São Paulo: Boitempo Editorial, 2004.

Filosofia, ideologia e ciência social. Tradução Ester Vaisman. São Paulo: Boitempo, 2008.

RANIÉRE, Jesus José. Alienação e estranhamento em Marx: dos manuscritos econômico-filosóficos de 1844 à ideologia alemã. Campinas (SP): 2000. Tese (Doutorado em Sociologia) - Programa de Pós-Graduação em Sociologia, Instituto de Filosofia e Ciências Humanas, Universidade Estadual de Campinas.

Recebido em 06/12/2017

Aprovado em 24/07/2018 